\title{
Effect of the combination of Education level and Business location on product quality: The Case Study of Arc Welding in Small Scale Metalworking Enterprises in Kenya
}

\author{
Charles M. M. Ondieki \\ Associate Professor, Multimedia University of Kenya \\ Chairman of TVET CDACC
}

\begin{abstract}
The quality of products from the micro and small enterprise sector is affected by both the entrepreneur's and enterprise's attributes. This paper presents and discusses findings of a study that was designed to investigate experimentally the relationship between the quality of arc in the Small Scale Metalwork sub-sector and the combined effect of the artisan's education level and business location. A total of $\mathbf{3 6}$ artisans with secondary education and $\mathbf{3 6}$ artisans with primary education consisting of formally (35) and informally (37) trained artisans from urban (29) and rural (43) areas participated in the evaluation. A mild steel product was fabricated by each participating artisan, assessed and scores awarded based on the quality of arc welding. The analysis of variance (ANOVA) was used to show any variation in the quality of arc welding; comparisons of means using the Least Significant Difference (LSD) at the alpha level of $5 \%$ were done to determine which pairs of artisans affected quality significantly. The study found out that artisans with secondary education performed better than those with primary education. The study also found out that artisans from urban areas performed better those from rural areas. The findings of this study provide evidence that higher level of education and urban location of business can improve product quality.
\end{abstract}

Key words: Education level, Business location, product quality, MSE, metalworking subsector, arc welding.

\section{INTRODUCTION}

The quality of products from the MSE sector is affected by both the entrepreneur's and enterprise's attributes. Many school leavers, retirees and retrenchees as well as those dissatisfied with formal wage employment resort to entrepreneurial activities within this sector as a means of earning a living. However, the Micro and Small Enterprise (MSE) sector entrepreneurs suffer various deficiencies in business management. These deficiencies are attributable to their low education levels and training, which in turn adversely affect their ability to produce high quality products among others. The influence of the entrepreneur's attributes such as age, gender, educational level, mode of training, work experience and membership to business support groups on the productivity and performance of enterprises has been reported. Similarly, enterprise attributes such as its age, location, ownership structure, and formal status and business activity determine production outcomes (Kimuyu, 2001).

This paper discusses the findings of a study that was designed to investigate experimentally the relationship between the quality of arc welding in the Small Scale Metalwork sub-sector and the artisan's level of education and the business location. The understanding and validation of this relationship is important for the effective marketing of the MSE products. 
Appropriate business knowledge gained through various paths such as school, previous employment experience and networking influence the entrepreneurial process (Baucus and Human, 1994). According to this study, informed people are likely to take fewer steps and easily succeed in overcoming business obstacles than the less informed ones. Product quality and value are directly dependent on technical and business knowledge. The ability for a product to compete in an open market would therefore depend on the quality of labour utilized in its production, which in turn depends on knowledge and skill levels among other factors. There is a need to show how education levels affect product quality quantitatively. Berihu (2008) examined the factors that determine productivity and export performance (export sales) of the garment sector in Ethiopia and found out that owner managers' education and firm size (economies of scale) have a positive impact on the export performance of an enterprise in the global value chains, while domestic sales have a negative impact.

The majority of the MSE/informal activities are in the rural areas or small towns and markets in Kenya. However, there is very little literature relating the performance of the MSEs and their business locations. Most of the literature available is on financial support to the sector followed by education and training in the MSE sector. Most of these studies have been carried out mainly in urban areas. Most of the previous studies obtained their data through the use of one or more of the following instruments: questionnaires, desk reviews, observations, interviews, focus group discussions, and content analysis. These studies were either qualitative or survey researches, while the present study was mainly experimental research (with a bit of qualitative using observation as far as the use of welding equipment and welding techniques are concerned to find out which groups - secondary/primary or urban/rural - were proficient or understood the welding process).

In arc welding processes the most common defects are either surface defects (cracks, distortion, overlaps and rolls, undercuts, excessive spatter, and bad weld surface appearance) or subsurface (hidden) weld defects. These defects (Parmar, 1997) come as a result of:

a) Improper selection of process, for example, using a very deep penetrating heat source on a narrow Vee angle so causing cracking in the root run due to large depth-to width ratio;

b) Applying the welding process incorrectly for the particular application, such as incorrect current setting or excess weld metal deposition;

c) The interaction of the weld metal with prior defects in the base metal, e.g. laminations and impurities like phosphorous, sulphur, and silicate, etc. that cause brittle and weak zones resulting in lamellar tearing;

d) Undesirable metallurgical structure with respect to grain size and hardness as well as undesirable inclusions such as tungsten oxide and slag. Hydrogen is a most undesirable inclusion as it is often the main cause of cold cracking in steels;

e) Undesirable shape and size of weld bead due to overfill and/or poor profile;

f) Incorrect joint preparations and poor fit-up leading to inaccessibility and lack of fusion, cracking, etc.;

g) Stray arcing, tool marks, undercuts, inclusions, poor finish, lack of fusion and penetration, and incorrect weld shape causing a reduction in fatigue life and joint strength;

All these are consequences of the level of training, experience and equipment used. For one to produce a quality product the sequence of welding techniques commonly used (Parmar, 1997), are: 
(a) The preliminary operations like cleaning, edge preparation, and the fixing of tab-in and tab-out plates are accomplished;

(b) Parts are assembled by tack welding or by employing jigs and fixtures;

(c) The assembled work piece is presented to the machine or vice versa;

(d) Welding is initiated by striking the arc for fusion welding or by bringing electrodes in contact with the work and switching on the current for resistance welding;

(e) Relative movement between the welding head and the work to attain the desired welding speed is created;

(f) The welding variables like arc voltage, welding current, and wire feed rate is controlled - controlling the welding variables like arc voltage controls the arc length, welding current, and wire feed rate;

(g) Welding process is stopped by stopping the relative movement between the welding head and the work;

(h) The welding head is shifted to the position the next welding cycle is to be initiated;

(i) The completed work is removed.

\section{Objective of the study}

The objective of this study was to investigate the Effect of the combination of education level and Business location on product quality from artisans in the metalworking sub-sector. The specific objectives were: To assess the relationship between the quality of arc welding and (a) Education level; (b) Business location; and (c) Education level and business location when combined.

\section{Hypotheses}

a) The Effect of Education level on Product quality:

i) There is no significant difference in product quality between all artisans with secondary education four form IV and all artisans with primary education standard eight.

b) The Effect of Business location on Product quality:

ii) There is no significant difference in product quality between all artisans working in urban areas and all artisans working in rural areas.

c) The Effect of the combination of Education level and Business location on product quality

iii) There is no significant difference in product quality between all artisans with secondary education four form IV working in urban areas and artisans with primary education standard eight working in urban areas.

iv) There is no significant difference in product quality between all artisans with secondary education four form IV working in rural areas and artisans with primary education standard eight working in rural areas.

v) There is no significant difference in product quality between artisans with secondary education four form IV working in urban areas and artisans with secondary education four form IV working in rural areas.

vi) There is no significant difference in product quality between all artisans with primary education standard eight working in urban areas and artisans with primary education standard eight working in rural areas.

\section{METHODOLOGY}

Sampling: The target population of the study consisted of experienced artisans who had completed class eight of the Kenyan primary education and experienced artisans who had 
completed form four of the Kenyan secondary education. The artisans were selected both from rural and urban areas with two modes of training (on-the-job training and formal technical training). The Kenyan MSE sector engages about 8.33 million operators (Government of Kenya, 2010). Out of this the Jua Kali sector (the MSEs that are engaged in technical work) is about $18 \%$ according to the National MSE baseline Survey conducted in 1999. The most widely used welding method is an arc welding for mild steel products, and according to the survey the number of artisans engaged in welding and fabrication is about 37,485 (Government of Kenya, 1999). About $60 \%$ and $40 \%$ of this number comprise primary education class eight graduates and secondary education form four graduates respectively (Government of Kenya, 2004). Based on these figures the total population for primary class eight artisans was taken to be 22,491 and for the secondary form four were taken to be 14,994. A total of 36 artisans with primary education class eight and a total of 36 artisans with secondary education form four were selected for assessment. The sample size determination was based on the relation:

$$
\begin{aligned}
& n=\frac{N c^{2}}{c^{2}+(N-1) e^{2}} ; \text { where } n=\text { sample size, and } N=\text { population size, } c \\
&=\text { coefficient of variation, }(\leq 30 \%), \text { and } e=\text { error of margin, }(\leq 5 \%) .
\end{aligned}
$$

This formula enabled the researchers to minimize the error and enhance stability of the estimates (Nassiuma, 2000). In this study $c$ was taken to be $30 \%$ and $e$ to be $5 \%$ (using the maximum percentage in each case). Table 1 show the number and category of artisans who participated in this study. The Directorate of Industrial Training (DIT) testing centers were used for this research. This was meant to minimize the effect on the quality of the fabricated products due to the condition of the welding equipment; (the welding equipment used in all DIT testing centers are more else of the same working condition).

Table 1: Number and category of participating artisans

\begin{tabular}{|c|c|c|c|}
\hline \multirow{2}{*}{ Education Level } & \multicolumn{2}{|c|}{ Business Location } & \multirow{2}{*}{ TOTAL } \\
\cline { 2 - 3 } & Urban Artisans & Rural Artisans & \\
\hline Secondary & 15 & 21 & $\mathbf{3 6}$ \\
\hline Primary & 14 & 22 & $\mathbf{3 6}$ \\
\hline TOTAL & $\mathbf{2 9}$ & $\mathbf{4 3}$ & $\mathbf{7 2}$ \\
\hline
\end{tabular}

Source: Author (2012)

The selected NITA testing centers were those with high concentrations of welders, and easily accessible by the researchers. A total of ten (10) NITA testing centers were used as shown in Table 2. Work started at the same time in all testing centers. Research assistants (who had been selected from among the NITA trained examiners) were used to supervise the participating artisans. 
Table 2: NITA Testing Centers and Number of Participating Artisans

\begin{tabular}{lcccc}
\hline NITA Centre (Province) & Education Level & Urban & Rural & Total \\
\hline 1. NIVTC (Nairobi) & Primary & 4 & 0 & 4 \\
2. Ruaraka (Nairobi) & Secondary & 5 & 1 & 6 \\
& Primary & 1 & 0 & 1 \\
3. Kakamega (Western) & Secondary & 3 & 0 & 3 \\
& Primary & 0 & 2 & 2 \\
4. Turbo (Western) & Secondary & 0 & 2 & 1 \\
& Primary & 0 & 4 & 4 \\
5. Kiambu (Central) & Secondary & 0 & 12 & 12 \\
& Primary & 0 & 4 & 4 \\
6. Machakos (Eastern) & Secondary & 0 & 1 & 1 \\
& Primary & 0 & 10 & 10 \\
7.Mombasa (Coast) & Secondary & 0 & 2 & 2 \\
& Primary & 5 & 0 & 5 \\
8. Eldoret (Rift Valley) & Secondary & 3 & 1 & 4 \\
9. Nakuru (Rift Valley) & Primary & 0 & 0 & 0 \\
& Secondary & 1 & 0 & 1 \\
10.Kisumu (Nyanza) & Primary & 0 & 1 & 1 \\
& Secondary & 1 & 1 & 2 \\
\hline & Primary & 4 & 1 & 5 \\
\hline & Secondary & 2 & 2 & 4 \\
\hline
\end{tabular}

The participating artisans were categorized into eight groups or strata as follows:

(a) Four strata (designated by G1 - G4) with secondary education Form IV:

(i) Formally trained artisans in urban areas (G1),

(ii) Formally trained artisans in rural areas G2),

(iii) Informally trained (Trained-on-the-job) artisans in urban areas (G3),

(iv) Informally trained (Trained-on-the-job) artisans in rural areas (G4),

(b) Four strata (designated by G5 - G8) with primary education standard VIII:

(i) Formally trained artisans in urban areas (G5),

(ii) Formally trained artisans in rural areas (G6),

(iii) Informally trained (Trained-on-the-job) artisans in urban areas (G7),

(iv) Informally trained (Trained-on-the-job) artisans in rural areas (G8),

Table 3: The Eight Groups of Participating Artisans

\begin{tabular}{|c|l|l|l|l|l|}
\hline \multirow{2}{*}{$\begin{array}{c}\text { Education } \\
\text { Level }\end{array}$} & \multicolumn{2}{|c|}{ Urban Location (29) } & \multicolumn{2}{c|}{ Rural Location (43) } & \multirow{2}{*}{ TOTAL } \\
\cline { 2 - 5 } & $\begin{array}{l}\text { Formally } \\
\text { Trained }\end{array}$ & $\begin{array}{l}\text { Informally } \\
\text { Trained }\end{array}$ & $\begin{array}{l}\text { Formally } \\
\text { Trained }\end{array}$ & $\begin{array}{l}\text { Informally } \\
\text { Trained }\end{array}$ & \\
\hline Secondary & Group 1 (5) & Group 3(10) & Group 2(14) & Group 4(7) & $\mathbf{3 6}$ \\
\hline Primary & Group 5 (6) & Group 7(8) & Group 6(10) & Group 8(12) & $\mathbf{3 6}$ \\
\hline TOTAL & $\mathbf{1 1}$ & $\mathbf{1 8}$ & $\mathbf{2 4}$ & $\mathbf{1 9}$ & $\mathbf{7 2}$ \\
\hline
\end{tabular}

Number of artisans per group is given in the brackets

Table 4: Mean Scores and Standard Deviations of Combined Groups of Artisans

\begin{tabular}{|c|c|c|c|c|}
\hline $\begin{array}{c}\text { Combined } \\
\text { Group }\end{array}$ & $\begin{array}{c}\text { Primary } \\
\text { Groups }\end{array}$ & $\begin{array}{c}\text { No. of } \\
\text { Artisans }\end{array}$ & $\begin{array}{c}\text { Mean } \\
\text { Score }\end{array}$ & $\begin{array}{c}\text { Standard } \\
\text { Deviation }\end{array}$ \\
\hline G13 (S/U) & Group 1 (G1) and Group 3 (G3) & 15 & 71.83 & 6.22 \\
\hline G57 (P/U) & Group 5 (G5) and Group 7 (G7) & 14 & 68.68 & 6.23 \\
\hline G24 (S/R) & Group 2 (G2) and Group 4 (G4) & 21 & 68.26 & 8.79 \\
\hline G68 (P/R) & Group 6 (G6) and Group 8 (G8) & 22 & 55.18 & 16.52 \\
\hline
\end{tabular}

$\boldsymbol{S} / \boldsymbol{U}$ - Secondary Urban; $\boldsymbol{S} / \boldsymbol{R}$ - Secondary Rural; $\boldsymbol{P} / \boldsymbol{U}$ - Primary Urban; $\boldsymbol{P} / \boldsymbol{R}$ - Primary Rural 


\section{The Evaluation of the Variables of the Study}

The independent variables of the study were the artisan's attribute (education level) and the business characteristics (business location), while the dependent variable was the scores awarded to indicate the quality of the product fabricated by the artisan by using arc welding processes.

\section{Evaluation of the Effect of Education Level}

The effect of education level was evaluated by comparing the mean scores of the following groups of artisans:

a) All artisans with secondary education form four and all artisans with primary education class eight $(\mathrm{GS} / \mathbf{P})$.

\section{Evaluation of the Effect of Business Location}

The effect of business location was also evaluated by comparing the mean scores of the following groups of artisans:

a) All artisans working in urban areas and all artisans working in rural areas (GU/R).

\section{Evaluation of the Effect of the combination of Education level and Business location}

The effect of the combination of Education level and Business location was evaluated by comparing the mean scores of the following groups of artisans:

a) All artisans with secondary education form four working in urban areas and all artisans with primary education class eight working in urban areas i.e., business location is constant (G13/57).

b) All artisans with secondary education form four working in rural areas and all artisans with primary education class eight working in rural areas i.e., business location is constant (G24/68).

c) All artisans with secondary education form four working in urban areas and all artisans with secondary education form four working in rural areas i.e., education level is constant (G13/24).

d) All artisans with primary education class eight working in urban areas and all artisans with primary education class eight working in rural areas i.e., education level is constant (G57/68).

\section{Data Generation Tools}

Two instruments were used to collect the required data. These were: i) Structured questionnaires, and ii) Assessment of fabricated product. The questionnaire was used mainly to get information regarding the artisan's attributes and business characteristics. The participating artisans were generally observed to find out how proficient they were in using the welding equipment and methods/techniques as outlined in the introduction.

\section{Assessment of Product Design}

A designed project shown in figures 1 was used in the research study. The product was to be fabricated using arc welding. The welding project was marked out of $100 \%$. The product was designed in such a way that most of the welding techniques were to be used in fabricating it. In this study, manual welding was employed; the artisans were given materials in the form of sheets and they were supposed to measure and cut the parts to the sizes shown. The parts were joined together using arc welding processes. The assessment was carried out by checking for the correct part sizes (by using Vernier calipers), and examining for the correct part alignment, correct welding and product finish; visual inspection was used to detect surface 
defects. Careful visual inspection of welds can detect about $80 \%$ to $90 \%$ of the defects and flaws (Parmar, 1997).

The quality of welded joints depends upon the design of the product, the performance of welding equipment, the welding procedures followed, and the skill of the operator. In this study any deficiency in the design and equipment affected all artisans equally. Therefore, the skill of the welder was to determine the scores obtained.

\section{Data Analysis}

\section{Data Analysis with the Use of SAS and ANOVA}

There were eight groups of data of participating artisans collected during the study; standard deviations for each group of artisans were calculated. The data (scores) collected were analyzed using the Statistical Analysis System (SAS) and Excel spreadsheet. The means and standard deviations were generated to describe the quality of arc welding with regard to education level and mode of training. The scores were matched with the artisans' attributes to find their relationships.

Since we were dealing with many factors that are influencing the experimental units, that is, the product quality from artisans, the ANOVA result was further analyzed using factorial analysis so as to find the factor with more influence on the artisans. This would enable one to test simultaneously the effects on the quality of arc welding of two different factors such as education level and business location.

The analysis of variance (ANOVA) was also used to show any variation in the quality of arc welding in each of the eight groups of participants/artisans due to the different treatments (e.g. Education levels and modes of training). Comparisons of all possible pairs of means using the alternative Least Significant Difference (LSD) method (this method is more appropriate to test unbalanced designs according to Webster, 1995, p.560) with alpha set at 5\% were done to determine which pairs of artisans engendered quality performances that were significantly different. Besides the analysis of variance results, differences in means of pairs of different primary groups and combined groups (i.e. Combination of various primary groups) was also analyzed using the alternative LSD method.

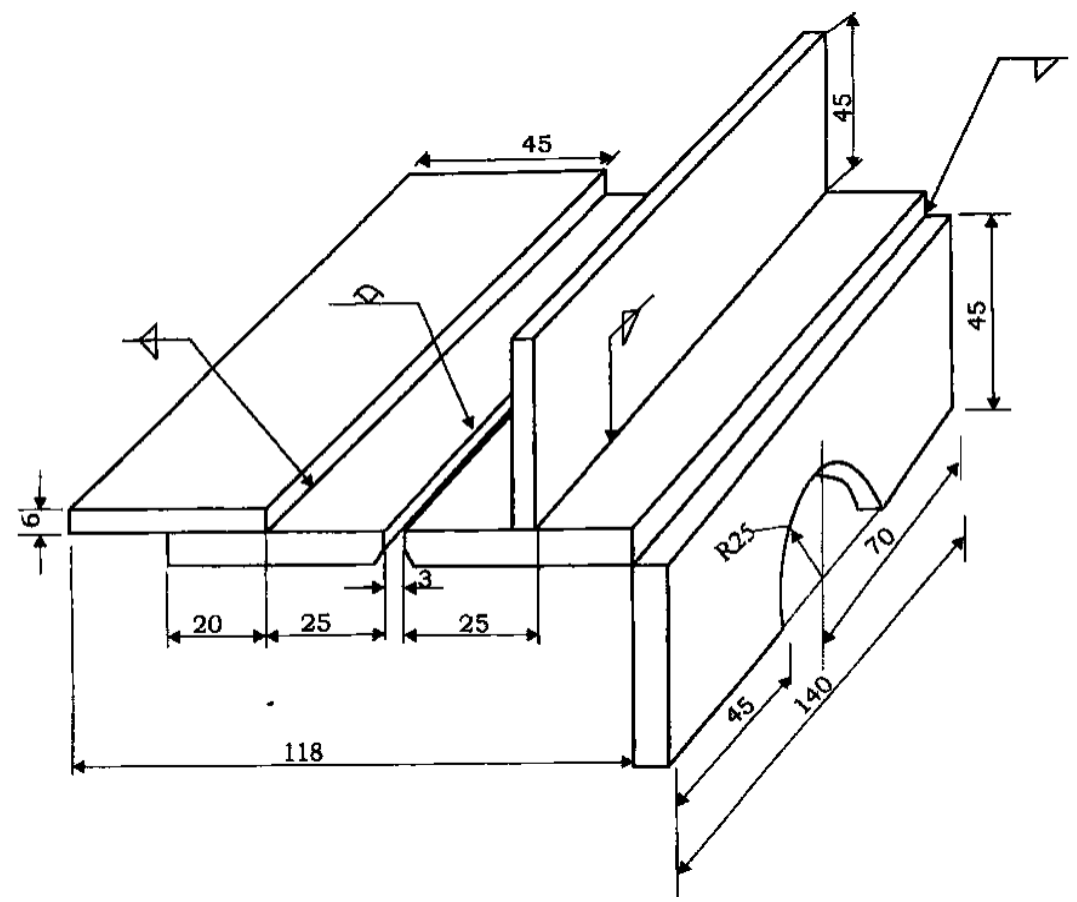

Figure 1. Mild steel welding project 


\section{Data Analysis with the Use of STATA Software}

Multicollinearity and heteroscedasticity were tested by the use of STATA software. Since the independent variables were categorical, a logistic model was derived and estimated using Ordinary Least Squares (OLS) through STATA software.

Multicollinearity refers to the extent to which an independent variable can be explained by other independent variables in the analysis and if too high this can have harmful effects on multiple regressions. Heteroscedasticity is a violation of one of the classical linear regression model assumptions that requires that the disturbances have the same variance. It is caused by several factors including the presence of outliers in the data, omitted variables, incorrect functional forms, and it is much more present in cross-sectional data.

\section{Data Analysis with the Use of SAS and ANOVA}

The data scores collected were analyzed using the Statistical Analysis System (SAS) and excel spreadsheet. The means and standard deviations were generated to describe the quality of arc welding with regard to the level of education and business location. The scores were matched with the artisans' attributes and business characteristics to find their relationships. The analysis of variance (ANOVA) was used to show any variation in the quality of arc welding in each of the eight groups of artisans due to the different treatments, that is, education level and business location. Comparisons of all possible pairs of means using the Least Significant Difference (LSD) method with alpha set at 5\% were done to determine which pairs of artisans with quality performances that was significantly different. The participating artisans totaling 36 with secondary education and 36 with primary education were further sub-divided into two groups of 29 artisans from urban areas and 43 artisans from rural areas. The artisans' scores awarded for quality of arc welding provided the data for determining the impact of education level and business location on product quality.

\section{RESULTS AND DISCUSSION \\ Effect of the Independent Variables on Product Quality}

The results of the investigation into the impact of the independent variables on product quality are presented in this section. The results of the investigation into the impact of the education level on product quality from artisans are presented first. The impacts of business locations on product quality from the artisans are presented in the second sub-section. In each sub-section the results are presented in a table. The table shows mean scores of product quality from combined groups of artisans for a particular attribute. Each column in this table contains pairs of artisans with a combination of attributes except one attribute which is common; here it is only one attribute being compared with, say education level while the other (business location) is assumed to have negligible effect on product quality. For example, in section one where the impact of education level is being investigated, all the two groups, in say column one, have business location as common and, which is being compared with education level.

\section{Effect of education level on product quality}

In terms of education, the eight primary groups could broadly be divided into two: those artisans with secondary education form four and those artisans with primary education standard eight. A total of 36 participants/artisans with secondary education were selected, while a total of 36 participants/artisans with primary education were also selected for this study. The artisans' scores for quality of arc welding provided the data for determining the effects or impact of education level on product quality. 
The first objective and hypothesis sought to determine whether there were differences in product quality when using arc welding processes from artisans with secondary education form four and primary education class eight. The analysis of variance was carried out and the results are presented in Tables 5 . Table 5 shows the mean scores of product quality for education levels from groups of artisans.

Table 5: Mean scores of product quality for education levels from groups of artisans

\begin{tabular}{cccc}
\hline Education Level & Urban & Rural & Overall Mean $^{\mathrm{a}}$ \\
\hline Secondary & G13: $71.87^{\mathrm{a}}$ & G24: $68.26^{\mathrm{a}}$ & GS: $\mathbf{6 9 . 9 6}^{\mathrm{a}}$ \\
Primary & G57: $68.68^{\mathrm{a}}$ & G68: $55.18^{\mathrm{c}}$ & GP: $\mathbf{6 0 . 4 3}^{\mathrm{b}}$ \\
\hline Mean Score & $\mathbf{7 0 . 3 3}$ & $\mathbf{6 1 . 5 7}$ & \\
\hline
\end{tabular}

The means followed by the same letter in the same column are not significantly different at $\alpha=5 \%$ using LSD

\section{Source: Author (2012)}

The results in Table 5 for both artisans with secondary and primary education working in urban areas show no significant differences, while the results for the rural artisans in both cases differ significantly with the secondary education holders having higher mean scores. This means that education level does not have a significant impact on product quality from artisans working in urban areas, but it does have a significant impact on product quality from artisans working in rural areas.

Overall the groups of artisans from urban areas exhibited higher product quality than those from rural areas. The overall mean scores are significantly different, with that for artisans with secondary education form four being higher than the mean score for artisans with primary education class eight.

The implication from this analysis is that the extra four years in school up to form four does not have any effect on product quality for urban artisans. On the other hand, the extra four years in school have a significant effect, resulting in an improved product quality from artisans working in rural areas. These results are consistent with the findings of Mullei (2003) in his study on small manufacturing firms where he sought to identify factors that determine firm growth and transformation among small firms in Kenya. The study covered food processing, woodworking, textile and garments, and metal working sub-sectors. The study found out that for an enterprise to graduate from, say micro to small enterprise, the education level and training of the manager/owner and the sector to which the enterprise belonged to, had a significant influence on enterprise graduation. Mullei (2003) also found out that more than half of small producers were primary school graduates whose ability to assimilate new technologies, innovate and imitate perfectly is limited. The study, therefore, recommends the raising of managerial, vocational and technical skills of small entrepreneurs for long-term industrial development. This shows the importance of higher level of education and formal training.

From the results generated using analysis of variance (ANOVA) and alternative LSD tests with mean scores for product quality from artisans presented in tables 5 , and as discussed above, it can be concluded that:

i) the first hypothesis: The null hypothesis that there is no significant difference in product quality between all artisans with secondary education four form IV and all artisans with primary education standard eight is rejected. 


\section{Effect of business location on product quality}

In terms of business location, the eight primary groups could broadly be divided into two: those artisans who were based in the urban areas and those artisans who were based in the rural areas. A total of 29 participants/artisans who were based in the urban areas were selected, while a total of 43 participants/artisans who were based in the rural areas were selected for evaluation in this study. The artisans' scores awarded for quality of arc welding provided the data for determining the effects or impact of business location on product quality.

The objective and hypothesis sought to determine whether there were differences in product quality when using arc welding processes by artisans based in urban areas and artisans based in rural areas. The analysis of variance was carried out and the results are presented in Tables 6. Table 6 shows mean scores of product quality for business locations from groups of artisans.

Table 6: Mean scores of product quality for business locations from groups of artisans

\begin{tabular}{|c|c|c|c|}
\hline \multirow{2}{*}{$\begin{array}{l}\text { Business } \\
\text { Location }\end{array}$} & \multicolumn{2}{|c|}{ Mean Scores } & \multirow{2}{*}{$\begin{array}{c}\text { Cumulative Mean } \\
\text { Scores }\end{array}$} \\
\hline & Secondary & Primary & \\
\hline Urban & G13: 71.83a & G57: 68.68a & GU: 70.33a \\
\hline Rural & G24: $68.26^{a}$ & G68: $55.18^{c}$ & GR: $61.57 b$ \\
\hline
\end{tabular}

Mean Scores

The means followed by the same letter in the same column are not significantly different at $\alpha=5 \%$ using LSD

\section{Source: Author (2012)}

Table 6 shows that there is no significant difference in the mean scores of the artisans with secondary and primary education in the urban areas. This implies that the business location does not have a significant impact on product quality when products are produced (using arc welding) by artisans with secondary education or with primary education.

However, there is significant difference in the mean scores of artisans with secondary education and artisans with primary education in the rural areas; the highest quality was exhibited by artisans with secondary education, while the lowest quality was exhibited by artisans with primary education. Overall, as the last column shows, artisans in urban areas emerged with the best product quality as compared with product quality from artisans in rural areas.

From the above analyses it can be concluded that both education level and business location have significant impact on product quality, with higher level of education and urban experience having higher positive impact on product quality. It can also be noticed that the high mean scores came from artisans in urban areas. This implies that urban experience contributes more significantly to product quality than education level alone. The results agree with Sonobe et al, (2000) who, when studying on the performance of garment enterprises in Jili, China, found out that the performance in producing quality products between enterprises in urban and remote centers (rural areas) were different; urban enterprises performed better than rural enterprises.

From the results generated using analysis of variance (ANOVA) and alternative LSD tests with mean scores for product quality from artisans presented in Table 6, and as discussed above, it can be concluded that:

i) the second hypothesis: The null hypothesis that there is no significant difference in product quality between all artisans working in urban areas and all artisans working in rural areas is rejected. 
In summary the findings from this specific objective are:

(a) The quality of arc welding from artisans working in the urban areas is higher than the quality of arc welding from artisans working in rural areas.

(b) The quality of arc welding from artisans with secondary education level working in the rural areas is higher than the quality of arc welding from artisans with primary education class eight working in the rural areas.

(c) Overall, the null hypothesis that there is no significant difference in product quality between artisans working in urban areas and artisans working in rural areas are rejected as evidenced from the last columns of the table of mean scores. This implies that business location alone has significant impact on product quality.

These results are consistent with the findings of Sonobe et al, (2003) who studied the changing role of innovation and imitation in the machine tool cluster in Taichung, Taiwan.They found out that primary graduates took 12.6 years to produce quality machine tools while high school and college graduates took 0.7 of a year to produce quality machine tools. This shows that higher education is essential in learning to produce high quality products.

In their study on measuring business skills cognition among informal sector business owners, Bosire and Gamba (2003) found that informal sector business owners differ in the various dimensions of business and in business skills cognition. The findings of their study conform to the view that knowledge is a very powerful tool in many respects, and spheres of modern living. Business practice, especially in a liberalized economy, requires the ability to know what to do and how to perform so as to manage the business and the clients. The ability to secure and utilize information is an important step towards identifying and possibly utilizing opportunities gainfully.

An informed business population is likely to be more effective and efficient in identifying and utilizing business opportunities. Hence higher level of education is very important. Some of the studies such as Luvanga (1998) and Bosire (2000) attribute problems of low competencies in business management among informal entrepreneurs to their low educational qualifications and achievements.

Earlier studies (ILO, 1972) described informal entrepreneurs as individuals with little or no formal education. The majority of the few who had attended formal schooling dropped out before completing the primary level. To compound the issue, most of them were poor achievers in class (Juma et al., 1993). Such arguments have been supported by Ghate et al. (1996) who categorized informal entrepreneurs into livelihood and micro-scale enterprises. The former was of lower educational qualification and were characterized by low incomes, little ambition to expand and basically subsistence in emphasis. The latter category comprised entrepreneurs with higher educational qualifications, with ambition to expand, hired labour and worked towards diversifying their investments.

In line with the above studies, this present study confirms that the artisans with primary education class eight suffer deficiency in production. This deficiency is attributable to low education levels, which in turn adversely affect their ability to produce quality products. On the other hand, the product quality from artisans with secondary education level was comparatively better because of their higher level of education. From this analysis it can be concluded that the urban artisans perform better than the rural artisans because they have more exposure and more information, have more work and therefore more experience, more competition, better equipment and tools, better methods of working, and more contact with other more experienced artisans. 


\section{Effect of the combination of Mode of training and Business location}

The third specific objective was to find out whether there is any relationship between product quality (quality of arc welding) and the combination of Education Level and Business location. The analysis of variance was carried out and the results are presented in Tables 5 and 6, which are used to evaluate the effect of the combination of Education level and Business location. The tables show mean scores of product quality for the combination of Education level and Business location from artisans.

From the results generated using analysis of variance (ANOVA) and alternative LSD tests with mean scores for product quality from artisans presented in tables 5 , and as discussed in section 3.2 above, it can be concluded that:

i) the third hypothesis: The null hypothesis that there is no significant difference in product quality between all artisans with secondary education four form IV working in urban areas and artisans with primary education standard eight working in urban areas is accepted.

ii) the fourth hypothesis: The null hypothesis that there is no significant difference in product quality between all artisans with secondary education four form IV working in rural areas and artisans with primary education standard eight working in rural areas is rejected.

From the results generated using analysis of variance (ANOVA) and alternative LSD tests with mean scores for product quality from artisans presented in tables 6 , and as discussed in section 3.3 above, it can be concluded that:

i) the fifth hypothesis: The null hypothesis that there is no significant difference in product quality between artisans with secondary education four form IV working in urban areas and artisans with secondary education four form IV working in rural areas is accepted.

ii) the sixth hypothesis: The null hypothesis that there is no significant difference in product quality between all artisans with primary education standard eight working in urban areas and artisans with primary education standard eight working in rural areas is rejected.

\section{Conclusions}

\section{CONCLUSIONS AND RECOMMENDATIONS}

The following are the conclusions drawn from this study:

1) Education and Business location have a significant impact on product quality; higher level of education (secondary) and urban work experience have higher positive impact on product quality as compared to lower education level (primary) and rural work experience.

2) Urban work experience contributes more significantly to product quality than education level alone.

3) Products made by artisans with primary education level are of lower quality than those products made by their counterparts with secondary education level.

4) The quality of products made by artisans (especially in the rural areas) can be improved by raising the standard of education, say from primary education class eight to secondary education level.

5) Overall, there is a significant difference in product quality between artisans working in urban areas and artisans working in rural areas as evidenced from the last columns of Tables 3 and 4 of mean scores. This implies that business location alone has significant impact on product quality. 


\section{Recommendations \\ Policy Recommendations}

a) Artisans with lower education and training are constrained by lack of adequate knowledge to enable them understand the welding theory on their own. From the study's findings and conclusions thereafter, the following recommendations have been drawn to help serve the MSE sector effectively and efficiently:

b) More resources should be directed towards training and raising education levels of artisans with low education and working in rural areas. Adult education strategies should be used to create and stimulate interest among the trainees.

c) Jua Kali artisans should be encouraged to take the Government Trade Tests up to at least Grade II so as to raise their competency level. The Kenya Bureau of Standards should also be asked to enforce quality standards in the informal sector.

\section{Recommendations for Further Research}

The following research activities are recommended in order to further augment the present achievements:

a) Research studies should be designed to investigate how other attributes besides the education level affect product quality and/or the performance of the MSE sector or other MSE sub-sectors

b) Research should also be conducted to investigate how the artisans' attributes and business characteristics affect the quality of product quality in other disciplines especially those that are mostly dominated by women, for example tailoring, tie and dye, embroidery, and basketry.

c) This study investigated the impact of the interaction of education level and business location in the metalwork sub-sector. Research studies should be designed to investigate how the interactions of other attributes affect product quality and/or the performance of the MSE sub-sectors.

d) Research should also be conducted to investigate how the interaction of education level and business location affect the quality of products in other disciplines especially those that are mostly dominated by women, such as tailoring, tie and dye, embroidery, and basketry.

\section{References}

Baucus A, Human S (1994). Second career entrepreneurs: A multiple case study analysis of entrepreneurial processes and antecedent variables. Entrepreneurship Theory and Practice, 19(2): 41-71.

Bosire J, Gamba P (2003). Measuring Business Skills Cognition: The Case of Informal Sector Entrepreneurs in Kenya. EASSRR, vol. XIX, No. 2

Bosire J (2000). The effect of education on business skills cognition among informal sector entrepreneurs. Ph.D. thesis, Kenyatta University, Nairobi.

Government of Kenya, (2010). Economic Survey 2010. Nairobi, Government Printer.

Government of Kenya (2005). Sessional Paper No.2 of Development of Micro and Small Enterprises for Wealth and Employment Creation for Poverty Reduction. Government Printers, Nairobi.

Government of Kenya, (2004). Directorate of Industrial Training Records on Trade Tests. Nairobi; DIT records Government of Kenya, (1999). National Micro and Small Enterprise Baseline Survey 1999. Nairobi: Government Printer

Government of Kenya (1997). Third draft report on Jua kali skills upgrading needs of micro and small enterprises training and technology project (MSETTP). Nairobi, Ministry of Research Technical Training and Technology.

ILO (1972). Employment, Incomes and Equality: A Strategy for Increasing Productive Employment in Kenya. Juma C, Torori C, Kirima C (1993). The adaptive economy: Economic crisis and technological innovation. Nairobi: ACTS Press. 
Kimuyu, P. (2001). Micro-Level Institutions \& Enterprise Productivity: Insights from Kenya's Small Business Sector.

Luvanga N (1998). The potential of the informal sector in poverty alleviation through employment and income generation in Tanzania. OSSREA Newsletter 16, 3: 11-18

Mullei A (2003). Growth and Transformation of Small Manufacturing Firms in Africa: Insights from Ghana, Kenya, and Zimbabwe, Nairobi: African Centre for Economic Growth.

Nassiuma D. K., (2000). Survey sampling: Theory and methods. Nairobi, University of Nairobi press.

Parmar R.S., (1997). Welding Engineering and Technology, First edition; Khana pubishers, New Delhi, India.

Sonobe T, Kawakami M, Otsuka K (2003). “Changing Roles of Innovation and Imitation in Industrial Development: A Case Study of a Machine Tool Industry in Taiwan," Economic Development and Cultural Change, 52(1): 103-128

Sonobe, T., Hu, D. and Otsuka, K. (2002). "Process of Cluster Formation in China: A Case Study of a Garment Town," Journal of Comparative Economics, Vol. 32, No. 3, pp. 542-563. 